\title{
REVIEW
}

\section{Ceftaroline Fosamil: A Brief Clinical Review}

Debbie-Ann T. Shirley • Emily L. Heil •

J. Kristie Johnson

To view enhanced content go to www.infectiousdiseases-open.com

Received: April 25, 2013 / Published online: August 8, 2013

(C) The Author(s) 2013. This article is published with open access at Springerlink.com

\section{ABSTRACT}

Ceftaroline is a novel cephalosporin with a favorable tolerability profile and broad in vitro activity against many resistant Gram-positive and common Gram-negative organisms. Ceftaroline fosamil is the first cephalosporin to be approved by the United States Food and Drug

D.-A. T. Shirley

Department of Pediatrics, Center for Vaccine Development, University of Maryland School of Medicine, Baltimore, USA

E. L. Heil

Department of Pharmacy, University of Maryland Medical Center, Baltimore, USA

J. K. Johnson ( $\varangle)$

Departments of Pathology and Epidemiology and Public Health, University of Maryland School of Medicine, $655 \mathrm{~W}$. Baltimore Street, Baltimore, MD 21201, USA

e-mail: jkjohnson@som.umaryland.edu

J. K. Johnson

Microbiology and Virology Laboratories, University of Maryland Medical Center, 22 S Greene St, Baltimore, MD 21201, USA
Administration (FDA) for the treatment of adults with acute bacterial skin and soft tissue infections, including those caused by methicillin-resistant Staphylococcus aureus (MRSA). It is also approved by the FDA for the treatment of adults with community-acquired bacterial pneumonia, including cases caused by Streptococcus pneumoniae (with or without concurrent bacteremia), although there are no data at this time to support the use of ceftaroline fosamil for the treatment of pneumonia caused by MRSA. Ceftaroline fosamil is likewise approved by the European Commission for the treatment of adults with complicated skin and soft tissue infections or community-acquired pneumonia. This review summarizes the pharmacokinetic and microbiologic properties of ceftaroline, as well as the safety and efficacy data that led to its approval by the FDA in 2010 and the European Commission in 2012. Future directions to be addressed are also highlighted.

Keywords: Avibactam;

Ceftaroline;

Cephalosporin; Community-acquired infection; Bacterial infection; Methicillinresistant $S$. aureus; Pneumonia; Skin infection; S. aureus; $S$. pneumoniae 


\section{INTRODUCTION}

Several authorities have called attention to the morbidity, mortality and excess health costs associated with antibiotic-resistant pathogens and the need to prioritize development of antibacterial agents that can safely and effectively treat these pathogens [1-4]. Ceftaroline fosamil is a novel cephalosporin, with bactericidal in vitro activity against pathogens associated with licensed indications, including resistant organisms, such as methicillin-resistant Staphylococcus aureus (MRSA), multidrug-resistant Streptococcus pneumoniae (MDRSP) and penicillin-resistant $S$. pneumoniae (PRSP) [5]. Supported by preclinical in vitro and animal model studies [6-10] and clinical trials [11-15], ceftaroline fosamil (Teflaro $^{\mathrm{TM}}$; Forest Laboratories, Inc., New York, USA) was approved by the United States Food and Drug Administration (FDA) in October 2010 for the treatment of adults with communityacquired bacterial pneumonia (CABP) and acute bacterial skin and skin structure infections (ABSSSI) caused by susceptible organisms [5]. Ceftaroline fosamil is the newest of only three systemic antibiotics approved for human use by the FDA over the past 5 years and the only one of these approved for the treatment of CABP. Similarly, the European Commission granted marketing authorization for ceftaroline fosamil (Zinforo $^{\mathrm{TM}}$; AstraZeneca, Södertälje, Sweden) in August 2012 for the treatment of communityacquired pneumonia and complicated skin and soft tissue infections following favorable opinion from the Committee for Medicinal Products for Human Use [16]. This report reviews the recent literature published on ceftaroline fosamil, including the pivotal clinical trials that led to its approval, and highlights areas that need to be addressed in the future.

\section{MECHANISM OF ACTION AND SPECTRUM OF ACTIVITY}

Similar to other $\beta$-lactam antibiotics, ceftaroline, the active metabolite of the prodrug ceftaroline fosamil, mediates its bactericidal effect by binding to membranebound enzymes known as penicillin-binding proteins (PBPs), thereby interfering with bacterial cell wall synthesis and leading to cell lysis and death [17]. Distinguishing it from other $\beta$-lactam antibiotics, however, is its unique high binding affinity for PBP 2a (which confers resistance to MRSA) and PBP 2b, 2x and 1a (which confer resistance to PRSP) $[18,19]$. The favorable activity of ceftaroline against clinical isolates, including potent activity against Gram-positive bacteria, such as MRSA, vancomycin-intermediate $S$. aureus (VISA) and PRSP, has been demonstrated in isolates collected worldwide [20] with corroboration from a number of in vitro and in vivo studies $[6,10,21-26]$, and maintained during in vitro attempts to generate resistant strains [27, 28]. Activity against Enterococcus faecalis and Enterococcus faecium is limited $[6,20]$. Ceftaroline's spectrum of activity against Gram-negative bacteria is comparable to that of many other cephalosporins, and it has no activity against extended-spectrum $\beta$-lactamase (ESBL) and carbapenemase-producing strains (e.g., Klebsiella pneumonia carbapenemase) or strains with stable de-repressed AmpC $\beta$ lactamase production [20, 27, 29]. In vitro activity against Gram-positive anaerobes is similar to that of amoxicillin-clavulanate, with good activity against Propionibacterium spp. and Actinomyces spp. [30, 31]. Ceftaroline is inactive against most $\beta$-lactamase-producing Gramnegative anaerobes, including Bacteroides fragilis and Prevotella spp. [30, 31]. 
Ceftaroline minimal inhibitory concentrations (MICs) and disk diffusion breakpoints have been defined by the FDA, and more recently by the Clinical Laboratory Standards Institute (CLSI) and the European Committee on Antimicrobial Susceptibility Testing (EUCAST) (Table 1) [5, 32, 33]. Due to the scarcity of resistant Gram-positive isolates at the time of licensing, only susceptible interpretations for Gram-positive strains are available from the FDA [5]. Target attainment analysis using Monte Carlo simulations support the FDA susceptible interpretative criteria for $S$. aureus (MIC $\leq 1 \mu \mathrm{g} / \mathrm{mL}$ ) when the recommended ceftaroline fosamil dosing regimen is used [34]. In vivo murine thigh infection models suggest that human simulated exposures of ceftaroline $600 \mathrm{mg}$ every $12 \mathrm{~h}$ may have efficacy in the treatment of $S$. aureus infections with MICs as high as $4 \mu \mathrm{g} / \mathrm{mL}$ [35], but more data on clinical outcomes associated with higher ceftaroline MICs are needed.

Results from the 2010 Assessing Worldwide Antimicrobial Resistance Evaluation (AWARE) program (Table 2) [36-42], a global ceftaroline surveillance study, showed that ceftaroline is highly active against $S$. aureus and MRSA among isolates collected from medical centers in nine United States census regions [36]. These high rates of $S$. aureus susceptibility were independent of patient age group [36]. Among respiratory pathogens, $98.7 \%$ of $S$. pneumoniae strains were inhibited by $0.25 \mu \mathrm{g} / \mathrm{mL}$ or less of ceftaroline, exhibiting potency 16 times greater than that of ceftriaxone [37]. During 2008-2010, there was sustained potency and activity against MRSA and MDRSP [defined as a $S$. pneumoniae isolate with resistance to at least two of the following antimicrobial agents: penicillin $\quad(\geq 8 \mu \mathrm{g} / \mathrm{mL}), \quad$ ceftriaxone, erythromycin, tetracycline, levofloxacin, and trimethoprim-sulfamethoxazole) and the frequency of non-susceptibility of respiratory pathogens to ceftaroline did not vary significantly [37, 38]. Geographic differences in activity among staphylococci, streptococci, Haemophilus spp., and Moraxella catarrhalis were minimal [39]. Susceptibility patterns to

Table 1 Food and Drug Administration (FDA), Clinical Laboratory Standards Institute (CLSI) and European Committee on Antimicrobial Susceptibility Testing (EUCAST) interpretive

minimum inhibitory concentration breakpoints $(\mu \mathrm{g} / \mathrm{mL})$ for ceftaroline $[5,32,33]$

\begin{tabular}{|c|c|c|c|c|c|c|c|c|}
\hline \multirow[t]{2}{*}{ Organism } & \multicolumn{3}{|l|}{ FDA $^{\mathbf{a}}$} & \multicolumn{3}{|l|}{ CLSI } & \multicolumn{2}{|c|}{ EUCAST } \\
\hline & $S$ & I & $\mathbf{R}$ & $\bar{S}$ & I & $\mathbf{R}$ & $\bar{S}$ & $\mathbf{R}$ \\
\hline Staphylococcus aureus & $\leq 1$ & - & - & $\leq 1$ & 2 & $\geq 4$ & $\leq 1$ & $>1$ \\
\hline Streptococcus pneumoniae & $\leq 0.25$ & - & - & $\leq 0.5^{\mathrm{c}}$ & - & - & $\leq 0.25$ & $>0.25$ \\
\hline Streptococcus agalactiae & $\leq 0.03$ & - & - & $\leq 0.5$ & & & d & $\mathrm{d}$ \\
\hline Streptococcus pyogenes & $\leq 0.015$ & - & - & $\leq 0.5$ & - & - & d & d \\
\hline Haemophilus influenzae & $\leq 0.12$ & - & - & $\leq 0.5$ & - & - & $\leq 0.03$ & $>0.03$ \\
\hline Enterobacteriaceae & $\leq 0.5$ & 1 & $\geq 2$ & $\leq 0.5$ & 1 & $\geq 2$ & $\leq 0.5$ & $>0.5$ \\
\hline
\end{tabular}

$I$ intermediate, $R$ resistant, $S$ susceptible

a Intermediate and resistant results not defined by the FDA for some pathogens

b Includes methicillin-resistant $S$. aureus

c Non-meningitis

d $\beta$-Lactam susceptibility of Streptococcus groups A, B, C and G is inferred from the penicillin susceptibility 


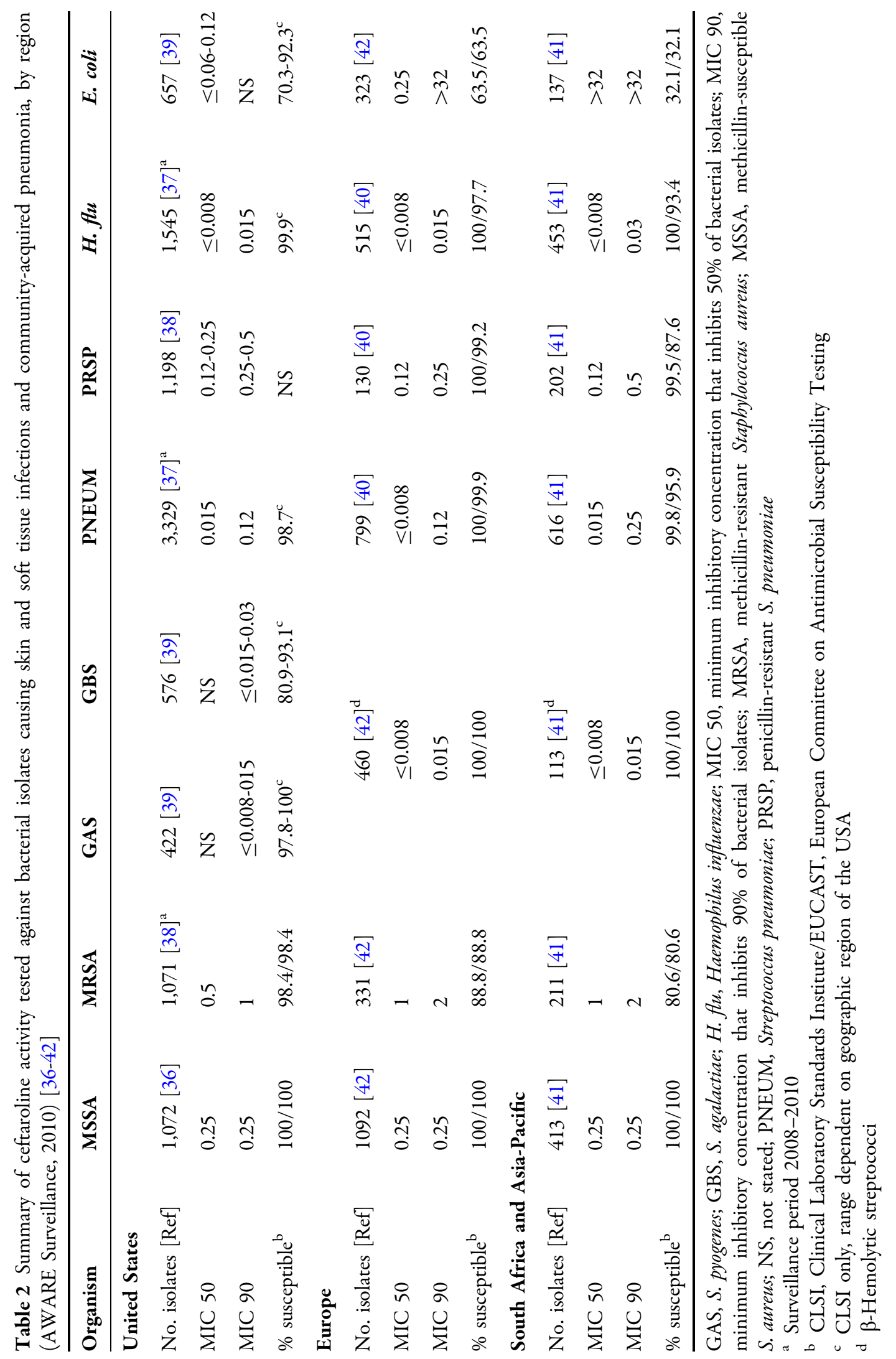


ceftaroline among MRSA isolates from Europe, South Africa and the Asia-Pacific region were lower than those seen in the USA, while consistently high rates of susceptibility to ceftaroline by methicillin-susceptible $S$. aureus, S. pneumoniae, Haemophilus influenzae and M. catarrhalis were maintained across all these regions [40-42]. Ongoing surveillance will be critical to determine whether resistant strains emerge from selective pressure elicited by more widespread use of ceftaroline. High rates of intermediate susceptibility of $S$. aureus to ceftaroline have already been noted in vitro among isolates from a surveillance program in China; $36.2 \%$ of the 315 isolates tested had an MIC above $1 \mu \mathrm{g} / \mathrm{mL}$, although the highest MIC documented was $2 \mu \mathrm{g} / \mathrm{mL}$ [43].

\section{DOSE AND ADMINISTRATION}

Following administration, the water-soluble prodrug, ceftaroline fosamil, is rapidly dephosphorylated to the active form in plasma [17]. For adults 18 years and older, the recommended dose is $600 \mathrm{mg}$ administered intravenously (IV) over $1 \mathrm{~h}$ every $12 \mathrm{~h}$. A treatment duration of 5-7 days for CABP and 5-14 days for ABSSSI is currently recommended, guided by the severity of infection and clinical response [5]. As with other $\beta$-lactam antibiotics, time above the MIC is the pharmacodynamic (PD) index that correlates best with efficacy [5]. Pharmacokinetic (PK) data in healthy adults with normal renal function following multiple doses administered every $12 \mathrm{~h}$ over 14 days show that the elimination half-life is about $2.7 \mathrm{~h}$, the maximum observed concentration $\left(C_{\max }\right)$ is $21 \mu \mathrm{g} / \mathrm{mL}$ and the area under the concentration-time curve is $56 \mu \mathrm{g} \mathrm{h} / \mathrm{mL}$, with no appreciable accumulation [5]. Ceftaroline is primarily renally excreted and dosage adjustment is recommended for patients with creatinine clearance $\left(\mathrm{CR}_{\mathrm{CL}}\right) \leq 50 \mathrm{~mL} / \mathrm{min}$. For patients with moderate renal impairment $\left(\mathrm{CR}_{\mathrm{CL}}\right.$ $>30$ to $\leq 50 \mathrm{~mL} / \mathrm{min}$ ), the dose should be adjusted to $400 \mathrm{mg}$ IV every $12 \mathrm{~h}$. For those with severe renal impairment $\left(\mathrm{CR}_{\mathrm{CL}} \geq 15\right.$ to $\leq 30 \mathrm{~mL} / \mathrm{min}$ ), the dose should be adjusted to $300 \mathrm{mg}$ IV every $12 \mathrm{~h}$ and for patients with endstage renal disease, including those receiving hemodialysis, adjustment to $200 \mathrm{mg}$ IV every $12 \mathrm{~h}$ after dialysis should be made [5].

Following a single IV radiolabeled dose, approximately $88 \%$ of radioactivity was recovered in urine and $6 \%$ in feces within $48 \mathrm{~h}$ [5]. Of the radioactivity recovered in urine, $64 \%$ was excreted as ceftaroline and approximately $2 \%$ as the microbiologically inactive ceftaroline M-1 metabolite, suggesting complete transformation of the prodrug [5]. Ceftaroline is primarily distributed in extracellular fluid and binding to plasma proteins is relatively low (approximately 20\%) [5]. In vitro studies demonstrate that ceftaroline is not a substrate for the cytochrome P450 system and it does not inhibit or induce the major cytochrome P450 isoenzymes. Therefore, there is minimal potential for drug-drug interactions between ceftaroline and drugs that are cytochrome P450 substrates, inhibitors, or inducers [5].

\section{CLINICAL EFFICACY}

\section{The FOCUS Trials}

The FOCUS (ceFtarOline Community-acquired pneUmonia trial vS ceftriaxone in hospitalized patients) 1 and 2 studies (NCT00621504 and NCT00509106, respectively) were multinational, multicenter, phase 3, double-masked, randomized, active comparator-controlled trials, designed to evaluate the safety and 
efficacy of ceftaroline fosamil $600 \mathrm{mg}$ IV every $12 \mathrm{~h}$ compared with ceftriaxone $1 \mathrm{~g}$ IV every $24 \mathrm{~h}$ for 5-7 days for the treatment of typical CABP in patients requiring hospital admission $[12,13,44$, 45]. Renal dose adjustments were based on creatinine clearance. For subjects enrolled in FOCUS 1 (which included North American participants), clarithromycin was administered during the first $24 \mathrm{~h}$ based on established practice guidelines advocating empiric macrolide use [46].

The primary objective of the studies was to determine whether the clinical cure rate of ceftaroline fosamil was non-inferior to that of ceftriaxone in the co-primary modified intentto-treat efficacy (MITTE) and clinically evaluable (CE) populations at the test-of-cure (TOC) visit (8-15 days after completion of therapy). The non-inferiority margin was set at $-10 \%$. The MITTE population included all participants in the pneumonia risk category (PORT) III or IV who received any amount of study drug according to their randomized treatment group. The CE population included participants in the MITTE population who demonstrated sufficient adherence to the protocol. Baseline characteristics and demographics were comparable between the two study arms and between the two studies. The majority of participants were Caucasian males over the age of 50 years recruited from Eastern and Western Europe. The most common pathogens isolated were $S$. pneumoniae $(41.7 \%)$ and $S$. aureus (16.5\%), followed by Gram-negative organisms, of which $H$. influenzae was the most frequent [44].

Clinical cure rates favored ceftaroline in a priori-defined integrated analysis of the MITTE and CE populations (Table 3) [12-15, 44, 47]. Planned secondary analysis of the CE subjects with at least one typical pathogen identified at baseline showed clinical cure in $85.1 \%$ of participants compared with $75.5 \%$ of participants in the ceftaroline and ceftriaxone groups, respectively [difference 9.7\%, 95\% confidence interval (CI) 0.7-18.8\%] [44]. Cure rates against $S$. pneumoniae, MDRSP and $S$. aureus favored ceftaroline, and were similar to ceftriaxone for Gram-negative pathogens [44]. The efficacy of ceftaroline against MRSA could not be evaluated as patients with suspected MRSA infection were excluded from enrollment (due to a lack of activity of ceftriaxone against MRSA). For bacteremia, cure rates were $71.4 \%$ (15 of 21 subjects) compared with $58.8 \%$ (10 of 17 subjects) for the ceftaroline and ceftriaxone groups, respectively (difference 12.6\%, 95\% CI $-17.6 \%$ to $41.6 \%$ ) [44]. At the late follow-up visit (21-35 days after completion of therapy), relapse rates between the two treatment arms were similar in the CE population: $1.9 \%$ for the ceftaroline group and $1.2 \%$ for the ceftriaxone group (difference $0.7 \%, 95 \% \mathrm{CI}-1.4 \%$ to $2.9 \%$ ) [44]. Pooled post hoc exploratory analysis requested by the FDA to assess clinical improvement on day 4 of study therapy in participants with a confirmed bacterial pathogen at baseline showed a weighted difference in clinical response of $11.4 \%$ (95\% CI 0.6-21.9\%) in favor of ceftaroline [48].

\section{The CANVAS Trials}

The CANVAS (CeftAroliNe Versus vAncomycin in Skin and skin structure infections) 1 and 2 studies (NCT00424190 and NCT00423657, respectively) were multinational, multicenter, phase 3, double-masked, randomized, active comparator-controlled trials designed to evaluate the safety and efficacy of monotherapy with ceftaroline fosamil $600 \mathrm{mg}$ IV every $12 \mathrm{~h}$ compared with a combination of vancomycin $1 \mathrm{~g}$ every $12 \mathrm{~h}$ plus aztreonam $1 \mathrm{~g}$ every $12 \mathrm{~h} \mathrm{IV}$ for 5-14 days for the treatment of 
ABSSSI [14, 15, 45, 47] Dose adjustments for renal impairment by unblinded pharmacists were based on creatinine clearance and institutional guidelines.

The primary objective of the studies was to determine whether the clinical cure rate of ceftaroline fosamil was non-inferior to that of vancomycin plus aztreonam in the co-primary modified intent-to-treat (MITT) and CE populations at the TOC visit (8-15 days after completion of therapy). The non-inferiority margin was set at $-10 \%$. The MITT population included all subjects who received any amount of study drug according to their randomized treatment group. The CE population included subjects in the MITT population who demonstrated sufficient adherence to the protocol. Baseline characteristics and demographics were comparable between the two study arms in each study. The majority of participants were Caucasian males with a median age of 48 years diagnosed with cellulitis, major abscesses and infected wounds/ulcers. Of the $76 \%$ of subjects with a pathogen isolated, $S$. aureus was the most common; the proportion with MRSA was $40 \%$ in the ceftaroline group and $34 \%$ in the vancomycin plus aztreonam group. Aztreonam or a saline placebo was discontinued if a Gramnegative pathogen was not identified.

A priori-defined integrated analysis of the primary endpoints demonstrated noninferiority of ceftaroline in the MITT and CE populations (Table 3 ). In a planned secondary analysis of participants in the CE population with at least one pathogen isolated, clinical cure was achieved in $92.7 \%$ of the subjects in the ceftaroline treatment group compared with

Table 3 Summary of clinical cure rate at the test-of-cure visit in the co-primary analysis populations, FOCUS and CANVAS trials [12-15, 44, 47]

\begin{tabular}{|c|c|c|c|c|c|c|}
\hline \multirow{3}{*}{$\begin{array}{l}\text { Trial } \\
\text { FOCUS }^{\mathbf{a}}\end{array}$} & \multicolumn{3}{|l|}{ MITTE } & \multicolumn{3}{|l|}{$\mathrm{CE}$} \\
\hline & \multicolumn{2}{|c|}{$\begin{array}{l}\text { Clinical cure \% } \\
\text { (no. of cured/total no.) }\end{array}$} & \multirow[t]{2}{*}{$\begin{array}{l}\text { Difference }^{\mathbf{b}} \\
(95 \% \mathrm{CI})\end{array}$} & \multicolumn{2}{|c|}{$\begin{array}{l}\text { Clinical cure \% } \\
\text { (no. of cured/total no.) }\end{array}$} & \multirow[t]{2}{*}{$\begin{array}{l}\text { Difference }^{b} \\
(95 \% \mathrm{CI})\end{array}$} \\
\hline & Ceftaroline & Ceftriaxone & & Ceftaroline & Ceftriaxone & \\
\hline 1 & $83.8(244 / 291)$ & $77.7(233 / 300)$ & $6.2(-0.2,12.6)$ & $86.6(194 / 224)$ & $78.2(183 / 234)$ & $8.4(1.4,15.4)$ \\
\hline 2 & $81.3(235 / 289)$ & $75.5(206 / 273)$ & $5.9(-1.0,12.7)$ & $82.1(193 / 235)$ & $77.2(166 / 215)$ & $4.9(-2.5,12.5)$ \\
\hline 1 and 2 & $82.6(479 / 580)$ & $76.6(439 / 573)$ & $6.0^{c}(1.4,10.7)$ & $84.3(387 / 459)$ & $77.7(349 / 449)$ & $6.7^{c}(1.6,11.8)$ \\
\hline Trial & MITT & & & $\mathrm{CE}$ & & \\
\hline \multirow[t]{2}{*}{ CANVAS $^{a}$} & \multicolumn{2}{|c|}{$\begin{array}{l}\text { Clinical cure \% } \\
\text { (no. cured/total no.) }\end{array}$} & $\begin{array}{l}\text { Difference }^{b} \\
(95 \% \mathrm{CI})\end{array}$ & \multicolumn{2}{|c|}{$\begin{array}{l}\text { Clinical cure \% } \\
\text { (no. cured/total no.) }\end{array}$} & \multirow[t]{2}{*}{$\begin{array}{l}\text { Difference } \\
(95 \% \mathrm{CI})\end{array}$} \\
\hline & Ceftaroline & Vanc/Az & & Ceftaroline & Vanc/Az & \\
\hline 1 & $86.6(304 / 351)$ & $85.6(297 / 347)$ & $1.0(-4.2,6.2)$ & $91.1(288 / 316)$ & $93.3(280 / 300)$ & $-2.2(-6.6,2.1)$ \\
\hline 2 & $85.1(291 / 342)$ & $85.5(289 / 338)$ & $-0.4(-5.8,5.0)$ & $92.2(271 / 294))$ & $92.1(269 / 292)$ & $0.1(-4.4,4.5)$ \\
\hline 1 and 2 & $85.9(595 / 693)$ & $85.5(586 / 685)$ & $0.3(-3.4,4.0)$ & $91.6(559 / 610)$ & $92.7(549 / 592)$ & $-1.1(-4.2,2.0)$ \\
\hline
\end{tabular}


94.4\% receiving combination therapy (difference $-1.7,95 \%$ CI $-4.9 \%$ to $1.6 \%$ ) at TOC [47]. In bacteremic subjects, cure rates were $84.6 \%$ (22 of 26 subjects) in the ceftaroline group compared to 100\% (21 of 21 subjects) in the combination group (difference $-15.4 \%$, $95 \%$ CI $-33.8 \%$ to $1.5 \%$ ) [47]. In particular, cure rates among subjects with S. aureus bacteremia were lower in the ceftaroline group (88.9\%), but not statistically different from the combination group (100\%) with, notably, twice as many subjects having $S$. aureus bacteremia in the ceftaroline group than in the combination group (18 vs. 9, respectively). At late follow-up (21-35 days after completion of therapy), clinical relapse rates were similar in the CE population: $1.1 \%$ and $0.9 \%$ in the ceftaroline and combination groups, respectively [47]. Post hoc analysis requested by the FDA to evaluate clinical response with cessation of lesion spread and apyrexia on day 3 of study therapy was conducted in a subgroup of 797 subjects and showed a weighted difference of 7.7\% (95\% CI 1.3-14.0\%) in favor of ceftaroline [49].

\section{SAFETY}

The safety profile of ceftaroline fosamil was evaluated in 1,740 participants and no unexpected safety concerns were identified [5, $48,50,51]$. In the integrated FOCUS analysis, the most common adverse events occurring in greater than $2 \%$ of subjects receiving ceftaroline fosamil were diarrhea $(4.2 \%)$, headache $(3.4 \%)$, insomnia (3.1\%) and phlebitis (2.8\%) [50]. In the integrated CANVAS analysis, the most common adverse events occurring in greater than $2 \%$ of subjects receiving ceftaroline fosamil were nausea (5.9\%), headache $(5.2 \%)$, diarrhea $(4.9 \%)$, pruritus $(3.5 \%)$, rash $(3.2 \%)$, generalized pruritus (2.2\%) and dizziness (2.0\%) [51]. Seroconversion to a positive direct anti-globulin (Coombs) test for the pooled data was higher in the ceftaroline group than comparator groups $(10.7 \%$ vs. $4.4 \%$, respectively), but was not associated with clinical hemolytic anemia [48]. Potential allergic reactions occurred in $5.4 \%$ of those treated with ceftaroline fosamil compared with $8.5 \%$ of those treated with a comparator regimen, $0.2 \%$ and $0.4 \%$ of these reactions were assessed as severe, respectively [48] Renal toxicity occurred in less than $2 \%$ and hepatic toxicity in less than 3\% of those treated with ceftaroline fosamil. Clostridium difficileassociated diarrhea and seizures were reported, but were rare [48].

Investigation of the effect of ceftaroline on human intestinal flora in adults who received infusions of ceftaroline fosamil IV every $12 \mathrm{~h}$ for 7 days revealed moderate decreases in the numbers of bifidobacteria and lactobacilli, with converse increases in the numbers of Clostridium spp., but minimal to no impact on Bacteroides spp. and aerobic bacteria [52]. Toxinproducing strains of $C$. difficile were isolated from two asymptomatic subjects. No measurable fecal concentrations of ceftaroline were found, which may have helped to explain the limited ecological disruptions observed [52]. At a dose of $1,500 \mathrm{mg}$, there was no clinically meaningful effect of ceftaroline fosamil on the QT interval [53]. There is no evidence of teratogenicity in animal studies, but controlled studies in pregnant or lactating women have not been performed [5]. Recently, isolated cases of eosinophilic pneumonia [54] and neutropenia [55] have been reported in patients receiving prolonged courses of ceftaroline; both events have been previously documented with cephalosporin use [56-60]. Overall, the cumulative data to date suggest 
that ceftaroline is well tolerated with a favorable safety profile, similar to the other drugs in the cephalosporin class.

\section{DISCUSSION}

\section{Current Role}

There is a need for alternative antimicrobials that can safely and effectively treat common but serious bacterial infections, such as complicated skin and skin structure infections and CABP caused by emergent antibiotic-resistant pathogens. In 2005, there were over 14 million outpatient visits made in the USA for ABSSSIs [61], which were among the most rapidly increasing reasons for hospitalizations between 1997 and 2007 [62-64], correlating with the rapid increase in the incidence of communityacquired MRSA infections between the mid1990s and 2005 [65]. There has been a great reliance on the glycopeptide, vancomycin, to treat MRSA, one of the most common pathogens associated with ABSSSIs, but resistant strains, including vancomycin-resistant $S$. aureus (VRSA) and VISA, have emerged [66]. In addition, the rate of treatment failure is higher in strains with an MIC of $1 \mu \mathrm{g} / \mathrm{mL}$ or greater, which includes some strains that would be classified as susceptible using current guidelines [67]. Vancomycin may also be inferior to $\beta$-lactam antibiotics for the treatment of methicillinsusceptible $S$. aureus bacteremia [68]. Other FDA-approved antibiotics for the treatment of MRSA include linezolid, daptomycin, tigecycline and telavancin. There have been reports of $S$. aureus treatment failures with daptomycin and linezolid [66] and toxicities associated with some of these options, such as myelosuppression myopathy and nephrotoxicity, are potentially limiting [69-
71]. Ceftaroline is a safe and effective option for the parenteral treatment of skin and soft tissue infections, especially in cases where empiric MRSA and common Gram-negative coverage are desired.

Pneumonia, another common but potentially life-threatening infection, together with influenza, consistently rank among the top ten leading causes of death for all ages in the USA each year, and accounted for more than 1.2 million hospitalizations in 2006 [72, 73]. Antibiotic susceptibility of $S$. pneumoniae, the most common cause of CABP, has decreased in the USA over the past decade. In 2009, only $84.1 \%, \quad 87.5 \%$ and $60.8 \%$ of surveyed S. pneumoniae isolates remained susceptible to penicillin, ceftriaxone and erythromycin, respectively [74]. Ceftaroline is active against resistant Gram-positive pathogens and is a safe, well-tolerated alternative option for the parenteral treatment of CABP. Recently, the incidence of pneumonia due to communityassociated MRSA has increased [46]. Ceftaroline's major important advantage compared to other $\beta$-lactam antibiotics, such as ceftriaxone, is its activity against MRSA. Although ceftaroline fosamil is approved for the treatment of adults with ABSSSI caused by MRSA, there are no official data to support its use in the specific treatment of CABP caused by MRSA. An experimental pneumonia model demonstrated significantly decreased bacterial counts in the lungs of neutropenic mice, suggesting the possible usefulness of ceftaroline for the treatment of MRSA pneumonia [6]. A trial of ceftaroline fosamil compared to ceftriaxone plus vancomycin in adults with CABP and at risk for MRSA infection is currently recruiting participants (NCT01645735) and will hopefully provide the clinical efficacy data needed to answer this question. 
No pharmacoeconomic analyses on the cost effectiveness of ceftaroline compared to other agents are available. Using average wholesale prices in US dollars, the approximate cost for a 10-day course of ceftaroline (600 mg IV twice daily at $\$ 119.96 /$ day) in a patient with normal renal function seems comparable to the range of costs for a similar course of other antibiotics with MRSA activity, including vancomycin ( $1 \mathrm{~g}$ IV twice daily at $\$ 9.40 /$ day), linezolid (600 mg IV twice daily at \$288.8/ day), daptomycin (500 mg IV once daily at $\$ 362.51 /$ day) and tigecycline (100 mg IV once daily or $50 \mathrm{mg}$ IV twice daily at $\$ 208.76 /$ day) [75]. Given the lack of clinical data in specific patient populations (such as those with MRSA pneumonia and bacteremia) and the demonstration of non-inferiority, rather than superiority, in phase 3 trials [44, 47], ceftaroline cannot currently be recommended over other alternative therapies for the treatment of CABP and ABSSSI, but should at least be considered in situations where concerns of resistance or toxicities may limit the use of other available drugs.

\section{Future Considerations}

Although ceftaroline has limited activity against resistant Gram-negative pathogens, time-kill experiments suggest extended coverage against resistant Enterobacteriaceae when combined with a $\beta$-lactamase inhibitor [76]. In vitro and animal studies demonstrated that avibactam, a non- $\beta$-lactam $\beta$-lactamase inhibitor, has potent synergistic activity with ceftaroline [29, 77-80]. Avibactam appears to inhibit ESBLs, including cephalosporinases and carbapenemases, and so may potentially enhance ceftaroline's spectrum of activity against Gram-negative bacteria. The development of a combination that offers such broad coverage is an exciting option for singleagent treatment of empiric or polymicrobial infections caused by multidrug-resistant Enterobacteriaceae and MRSA [81]. Ceftobiprole, another new generation cephalosporin approved for use in some countries for the treatment of complicated skin and soft tissue infections (however, rejected by the FDA in 2009 and the European Medicines Agency in 2010) has extended Grampositive activity similar to that of ceftaroline, and Gram-negative coverage similar to that of ceftazidime, but unlike ceftaroline-avibactam, ceftobiprole remains susceptible to hydrolysis by several ESBLs $[82,83]$. Ceftaroline-avibactam was well tolerated in a phase 1 trial without demonstrating significant PK interaction when administered concomitantly [84]. A phase 2 trial for the treatment of complicated urinary tract infections (NCT01281462) has been completed.

Animal models have been established to evaluate the in vivo efficacy of ceftaroline in the treatment of endocarditis, osteomyelitis and meningitis [8, 9, 24, 85, 86]. Following a 4-day course of ceftaroline fosamil in a rabbit endocarditis model, ceftaroline demonstrated superior bactericidal activity against MRSA and heterogeneous VISA when compared to vancomycin and linezolid [9]. Similarly, ceftaroline fosamil demonstrated significant bactericidal activity against MRSA and VISA, with a greater than $5 \log _{10}$ colony-forming unit/g reduction of vegetation, which was comparable to that of daptomycin and superior to that of tigecycline [24]. When compared to vancomycin and linezolid, ceftaroline demonstrated improved bacterial killing of vancomycin-sensitive and vancomycin-resistant $E$. faecalis in both timekill experiments and a rabbit endocarditis model [8]. Significant colony count reductions 
in infected joint and bone tissues were seen following a 4-day course of ceftaroline in an experimental rabbit model of acute MRSA osteomyelitis, which was comparable to that of linezolid and significantly better than that of vancomycin, indicating ceftaroline has good bone and joint penetration [85]. Ceftaroline was superior to cefepime against Klebsiella pneumoniae in a rabbit meningitis model; the penetration of ceftaroline into inflamed and non-inflamed meninges was estimated to be $15 \%$ and $3 \%$, respectively [86].

Reports of off-label use of ceftaroline are also emerging. Prompt sterilization of blood following the addition of ceftaroline salvage therapy was documented in a review of six cases of persistent or recurrent MRSA bacteremia/ endocarditis being treated with vancomycin or daptomycin [87, 88]. Interestingly, the five patients treated with a more aggressive regimen of ceftaroline $600 \mathrm{mg}$ administered every $8 \mathrm{~h}$ all survived, while the patient who received ceftaroline every $12 \mathrm{~h}$ succumbed to other complications [87]. A case report documented clearance of blood within 4 days of the addition of ceftaroline in a patient with endocarditis failing daptomycin therapy, and is supported by an in vitro PK/PD model, which showed that the addition of ceftaroline enhances daptomycin susceptibility [88]. A similar PK/PD model showed that ceftaroline increases membrane binding and enhances the activity of daptomycin against daptomycinsusceptible and non-susceptible strains of MRSA, suggesting potency of this combination [89]. Ceftaroline has also been used for the treatment of prosthetic joint infections [90] and in a patient with osteomyelitis and endocarditis [91]. Though clinical data on the use of ceftaroline for the treatment of infections other than CABP and ABSSSI are lacking, cumulatively, these in vivo animal studies and case reports provide early evidence that ceftaroline may potentially prove useful in the treatment of other serious bacterial infections.

Due to insufficient safety, PK and efficacy data, antibiotic options with MRSA activity in children are even more limited than in the adult population [92]. Pediatric trials evaluating the safety and efficacy of ceftaroline for the treatment of CABP and complicated skin infections are currently recruiting patients (NCT01530763, NCT01669980 and NCT01400867). A cephalosporin with antiMRSA activity may prove valuable, as $\beta$-lactam antibiotics are a popular choice for the treatment of infections in children, given their favorable safety profiles. As these and other post-marketing studies are underway, other areas to systematically address in the future include the effectiveness of ceftaroline in the treatment of immunocompromised patients, patients with septic shock and those with necrotizing fasciitis. Ongoing surveillance studies will also be necessary.

\section{CONCLUSION}

Ceftaroline fosamil is a well-tolerated and welcome addition to the available antibiotic options for the treatment of the increasing number of resistant Gram-positive and common Gram-negative infections. Clinical trials have demonstrated that the efficacy of ceftaroline fosamil is similar to that of comparator agents in the treatment of ABSSSI and CABP. Its lack of activity against resistant Gram-negative pathogens limits its current use as a monotherapeutic agent for the treatment of hospital-acquired infections, but with the addition of a $\beta$-lactamase inhibitor, such as avibactam, its activity may prove to be safely extended. Additional trials to further define the 
efficacy of ceftaroline in the treatment of other serious bacterial infections will be beneficial, as will safety and efficacy data in children.

\section{ACKNOWLEDGMENTS}

No funding or sponsorship was received for this study or publication of this article. Dr. Johnson is the guarantor for this article, and takes responsibility for the integrity of the work as a whole.

Conflict of interest. Kristie Johnson has received research grants from Nanosphere, BioFire, and Bio-Med Protect. Debbie-Ann Shirley and Emily Heil declare no conflict of interest.

Open Access. This article is distributed under the terms of the Creative Commons Attribution Noncommercial License which permits any noncommercial use, distribution, and reproduction in any medium, provided the original author(s) and the source are credited.

\section{REFERENCES}

1. Boucher HW, Talbot GH, Bradley JS, et al. Bad bugs, no drugs: no ESKAPE! An update from the Infectious Diseases Society of America. Clin Infect Dis. 2009;48:1-12.

2. The $10 \times 20$ Initiative: pursuing a global commitment to develop 10 new antibacterial drugs by 2020. Clin Infect Dis. 2010;50:1081-3.

3. Nordberg P, Monnet DL, Cars O. Antibacterial drug resistance [priority medicines for Europe and the world, a public health approach to innovation]; 2004. http://soapimg.icecube.snowfall.se/stopresistance/Priority_Medicine_Antibacterial_background_ docs_final.pdf (Accessed 27 Jan 2013).

4. The bacterial challenge: time to react. European Centre for Disease Prevention and Control/ European Medicines Agency Joint Technical Report; 2009. http://www.emea.europa.eu/pdfs/
human/antimicrobial_resistance/EMEA-576176-2009. pdf (Accessed 27 Jan 2013).

5. TEFLARO ${ }^{\circledR}$ (ceftaroline fosamil) [prescribing information]. St. Louis: Forest Pharmaceuticals, Inc.; 2012.

6. Iizawa $\mathrm{Y}$, Nagai J, Ishikawa $\mathrm{T}$, et al. In vitro antimicrobial activity of T-91825, a novel antiMRSA cephalosporin, and in vivo anti-MRSA activity of its prodrug, TAK-599. J Infect Chemother. 2004;10:146-56.

7. Jacqueline C, Caillon J, Batard E, et al. Evaluation of the in vivo efficacy of intramuscularly administered ceftaroline fosamil, a novel cephalosporin, against a methicillin-resistant Staphylococcus aureus strain in a rabbit endocarditis model. J Antimicrob Chemother. 2010;65:2264-5.

8. Jacqueline $\mathrm{C}$, Caillon $\mathrm{J}$, Le Mabecque $\mathrm{V}$, et al. In vivo activity of a novel anti-methicillin-resistant Staphylococcus aureus cephalosporin, ceftaroline, against vancomycin-susceptible and -resistant Enterococcus faecalis strains in a rabbit endocarditis model: a comparative study with linezolid and vancomycin. Antimicrob Agents Chemother. 2009;53:5300-2.

9. Jacqueline C, Caillon J, Le Mabecque V, et al. In vivo efficacy of ceftaroline (PPI-0903), a new broad-spectrum cephalosporin, compared with linezolid and vancomycin against methicillinresistant and vancomycin-intermediate Staphylococcus aureus in a rabbit endocarditis model. Antimicrob Agents Chemother. 2007;51:3397-400.

10. Croisier-Bertin D, Piroth L, Charles PE, et al. Ceftaroline versus ceftriaxone in a highly penicillin-resistant pneumococcal pneumonia rabbit model using simulated human dosing. Antimicrob Agents Chemother. 2011;55:3557-63.

11. Talbot GH, Thye D, Das A, Ge Y. Phase 2 study of ceftaroline versus standard therapy in treatment of complicated skin and skin structure infections. Antimicrob Agents Chemother. 2007;51:3612-6.

12. File TM Jr, Low DE, Eckburg PB, et al. FOCUS 1: a randomized, double-blinded, multicentre, Phase III trial of the efficacy and safety of ceftaroline fosamil versus ceftriaxone in community-acquired pneumonia. J Antimicrob Chemother. 2011;66:iii19-32.

13. Low DE, File TM Jr, Eckburg PB, et al. FOCUS 2: a randomized, double-blinded, multicentre, Phase III trial of the efficacy and safety of ceftaroline fosamil versus ceftriaxone in community-acquired pneumonia. J Antimicrob Chemother. 2011;66:iii33-44. 
14. Corey GR, Wilcox MH, Talbot GH, Thye D, Friedland D, Baculik T. CANVAS 1: the first Phase III, randomized, double-blind study evaluating ceftaroline fosamil for the treatment of patients with complicated skin and skin structure infections. J Antimicrob Chemother. 2010;65(Suppl 4):iv41-51.

15. Wilcox MH, Corey GR, Talbot GH, Thye D, Friedland D, Baculik T. CANVAS 2: the second Phase III, randomized, double-blind study evaluating ceftaroline fosamil for the treatment of patients with complicated skin and skin structure infections. J Antimicrob Chemother. 2010;65: iv53-65.

16. AstraZeneca press releases. European Commission approves ZINFORO ${ }^{\mathrm{TM}}$ (ceftaroline fosamil) for adult patients with serious skin infections or community acquired pneumonia. August 28, 2012 [January 29, 2013]. http://www.astrazeneca.com/Media/Pressreleases/Article/28082012-european-commissionapproves-zinforo. (Accessed 8 March 2013).

17. Ishikawa $T$, Matsunaga $N$, Tawada $H$, Kuroda $N$, Nakayama Y, Ishibashi Y, Tomimoto M, Ikeda Y, Tagawa Y, Iizawa Y, Okonogi K, Hashiguchi S, Miyake A. TAK-599, a novel N-phosphono type prodrug of anti-MRSA cephalosporin T-91825: synthesis, physicochemical and pharmacological properties. Bioorg Med Chem. 2003;11:2427-37.

18. Zapun A, Contreras-Martel C, Vernet T. Penicillinbinding proteins and beta-lactam resistance. FEMS Microbiol Rev. 2008;32:361-85.

19. Kosowska-Shick K, McGhee PL, Appelbaum PC. Affinity of ceftaroline and other beta-lactams for penicillin-binding proteins from Staphylococcus aureus and Streptococcus pneumoniae. Antimicrob Agents Chemother. 2010;54:1670-7.

20. Sader HS, Fritsche TR, Kaniga K, Ge Y, Jones RN. Antimicrobial activity and spectrum of PPI-0903M (T-91825), a novel cephalosporin, tested against a worldwide collection of clinical strains. Antimicrob Agents Chemother. 2005;49:3501-12.

21. Sader HS, Fritsche TR, Jones RN. Antimicrobial activities of Ceftaroline and ME1036 tested against clinical strains of community-acquired methicillinresistant Staphylococcus aureus. Antimicrob Agents Chemother. 2008;52:1153-5.

22. Vidaillac C, Leonard SN, Rybak MJ. In vitro activity of ceftaroline against methicillin-resistant Staphylococcus aureus and heterogeneous vancomycin-intermediate $S$. aureus in a hollow fiber model. Antimicrob Agents Chemother. 2009;53:4712-7.

23. Saravolatz L, Pawlak J, Johnson L. In vitro activity of ceftaroline against community-associated methicillin-resistant, vancomycin-intermediate, vancomycin-resistant, and daptomycinnonsusceptible Staphylococcus aureus isolates. Antimicrob Agents Chemother. 2010;54:3027-30.

24. Jacqueline C, Amador G, Batard E, et al. Comparison of ceftaroline fosamil, daptomycin and tigecycline in an experimental rabbit endocarditis model caused by methicillinsusceptible, methicillin-resistant and glycopeptideintermediate Staphylococcus aureus. J Antimicrob Chemother. 2011;66:863-6.

25. Zhanel GG, Rossnagel E, Nichol K, et al. Ceftaroline pharmacodynamic activity versus communityassociated and healthcare-associated methicillinresistant Staphylococcus aureus, heteroresistant vancomycin-intermediate $S$. aureus, vancomycinintermediate $S$. aureus and vancomycin-resistant $S$. aureus using an in vitro model. J Antimicrob Chemother. 2011;66:1301-5.

26. Steed M, Vidaillac C, Rybak MJ. Evaluation of ceftaroline activity versus daptomycin (DAP) against DAP-nonsusceptible methicillin-resistant Staphylococcus aureus strains in an in vitro pharmacokinetic/pharmacodynamic model. Antimicrob Agents Chemother. 2011;55:3522-6.

27. Mushtaq S, Warner M, Ge Y, Kaniga K, Livermore DM. In vitro activity of ceftaroline (PPI-0903M, T-91825) against bacteria with defined resistance mechanisms and phenotypes. J Antimicrob Chemother. 2007;60:300-11.

28. Clark C, McGhee P, Appelbaum PC, Kosowska-Shick K. Multistep resistance development studies of ceftaroline in Gram-positive and -negative bacteria. Antimicrob Agents Chemother. 2011;55:2344-51.

29. Mushtaq S, Warner M, Williams G, Critchley I, Livermore DM. Activity of chequerboard combinations of ceftaroline and NXL104 versus beta-lactamase-producing Enterobacteriaceae. J Antimicrob Chemother. 2010;65:1428-32.

30. Citron DM, Tyrrell KL, Merriam CV, Goldstein EJ. In vitro activity of ceftaroline against 623 diverse strains of anaerobic bacteria. Antimicrob Agents Chemother. 2010;54:1627-32.

31. Snydman DR, Jacobus NV, McDermott LA. In vitro activity of ceftaroline against a broad spectrum of recent clinical anaerobic isolates. Antimicrob Agents Chemother. 2011;55:421-5.

32. Clinical and Laboratory Standards Institute. Performance standards for antimicrobial susceptibility testing; twenty-third informational supplement. CLSI document M100-S23 (ISBN156238-866-5). Wayne: Clinical and Laboratory Standards Institute; 2013. 
33. EUCAST Breakpoint tables for interpretation of MICs and zone dimeters. Version 3.1. European Committee on Antimicrobial Susceptibility Testing 2013. http://www.eucast.org/fileadmin/ src/media/PDFs/EUCAST_files/Breakpoint_tables/ Breakpoint_table_v_3.1.pdf (Accessed 5 Feb 2013).

34. Drusano GL. Pharmacodynamics of ceftaroline fosamil for complicated skin and skin structure infection: rationale for improved anti-methicillinresistant Staphylococcus aureus activity. J Antimicrob Chemother. 2010;65:iv33-9.

35. Keel RA, Crandon JL, Nicolau DP. Efficacy of human simulated exposures of ceftaroline administered at 600 milligrams every 12 hours against phenotypically diverse Staphylococcus aureus isolates. Antimicrob Agents Chemother. 2011;55:4028-32.

36. Sader HS, Flamm RK, Farrell DJ, Jones RN. Activity analyses of staphylococcal isolates from pediatric, adult, and elderly patients: AWARE Ceftaroline Surveillance Program. Clin Infect Dis. 2012;55:S181-6.

37. Pfaller MA, Farrell DJ, Sader HS, Jones RN. AWARE Ceftaroline Surveillance Program (2008-2010): trends in resistance patterns among Streptococcus pneumoniae, Haemophilus influenzae, and Moraxella catarrhalis in the United States. Clin Infect Dis. 2012;55:S187-93.

38. Farrell DJ, Castanheira M, Mendes RE, Sader HS, Jones RN. In vitro activity of ceftaroline against multidrug-resistant Staphylococcus aureus and Streptococcus pneumoniae: a review of published studies and the AWARE Surveillance Program (2008-2010). Clin Infect Dis. 2012;55:S206-14.

39. Flamm RK, Sader HS, Farrell DJ, Jones RN. Ceftaroline potency among 9 US Census regions: report from the 2010 AWARE Program. Clin Infect Dis. 2012;55:S194-205.

40. Farrell DJ, Flamm RK, Jones RN, Sader HS. Spectrum and potency of ceftaroline tested against leading pathogens causing community-acquired respiratory tract infections in Europe (2010). Diagn Microbiol Infect Dis. 2013;75:86-8.

41. Sader HS, Flamm RK, Jones RN. Antimicrobial activity of ceftaroline and comparator agents tested against bacterial isolates causing skin and soft tissue infections and community-acquired respiratory tract infections isolated from the AsiaPacific region and South Africa (2010). Diagn Microbiol Infect Dis. 2013;76:61-8.

42. Farrell DJ, Flamm RK, Sader HS, Jones RN. Spectrum and potency of ceftaroline tested against leading pathogens causing skin and soft-tissue infections in Europe (2010). Int J Antimicrob Agents. 2013;41:337-42.

43. Zhang H, Xiao M, Yang QW, et al. High ceftaroline non-susceptibility in Staphylococcus aureus isolated from acute skin infections in 15 tertiary hospitals in China. J Med Microbiol. 2012;62:496-7.

44. File $\mathrm{TM} \mathrm{Jr}$, Low DE, Eckburg PB, et al. Integrated analysis of FOCUS 1 and FOCUS 2: randomized, doubled-blinded, multicenter phase 3 trials of the efficacy and safety of ceftaroline fosamil versus ceftriaxone in patients with communityacquired pneumonia. Clin Infect Dis. 2010;51:1395-405.

45. File TM Jr, Wilcox MH, Stein GE. Summary of ceftaroline fosamil clinical trial studies and clinical safety. Clin Infect Dis. 2012;55:S173-80.

46. Mandell LA, Wunderink RG, Anzueto A, et al. Infectious Diseases Society of America/American Thoracic Society consensus guidelines on the management of community-acquired pneumonia in adults. Clin Infect Dis. 2007;44:S27-72.

47. Corey GR, Wilcox M, Talbot GH, et al. Integrated analysis of CANVAS 1 and 2: phase 3, multicenter, randomized, double-blind studies to evaluate the safety and efficacy of ceftaroline versus vancomycin plus aztreonam in complicated skin and skinstructure infection. Clin Infect Dis. 2010;51:641-50.

48. Forest Research Institute I. Briefing bookceftaroline fosamil for injection; 2010. http:// www.fda.gov/downloads/advisorycommittees/committeesmeetingmaterials/drugs/anti-infectivedrugs advisorycommittee/ucm224657.pdf (Accessed 9 July 2013).

49. Friedland HD, O'Neal T, Biek D, et al. CANVAS 1 and 2: analysis of clinical response at day 3 in two phase 3 trials of ceftaroline fosamil versus vancomycin plus aztreonam in treatment of acute bacterial skin and skin structure infections. Antimicrob Agents Chemother. 2012;56:2231-6.

50. Rank DR, Friedland HD, Laudano JB. Integrated safety summary of FOCUS 1 and FOCUS 2 trials: phase III randomized, double-blind studies evaluating ceftaroline fosamil for the treatment of patients with community-acquired pneumonia. J Antimicrob Chemother. 2011;66:iii53-9.

51. Corrado ML. Integrated safety summary of CANVAS 1 and 2 trials: Phase III, randomized, double-blind studies evaluating ceftaroline fosamil for the treatment of patients with complicated skin and skin structure infections. J Antimicrob Chemother. 2010;65:iv67-71. 
52. Panagiotidis G, Backstrom T, Asker-Hagelberg C, Jandourek A, Weintraub A, Nord CE. Effect of ceftaroline on normal human intestinal microflora. Antimicrob Agents Chemother. 2010;54:1811-4.

53. Riccobene TA, Rekeda L, Rank D, Llorens L. Evaluation of the effect of a supratherapeutic dose of intravenous ceftaroline fosamil on the corrected QT interval. Antimicrob Agents Chemother. 2013;57:1777-83.

54. Desai KR, Burdette SD, Polenakovik HM, Hagaman J, Pleiman CM. Ceftaroline-induced eosinophilic pneumonia. Pharmacotherapy. 2013;33:e166-9.

55. Rimawi RH, Frenkel A, Cook PP. Ceftaroline-a cause for neutropenia. J Clin Pharm Ther. 2013;38:330-2.

56. Dreis DF, Winterbauer RH, Van Norman GA, Sullivan SL, Hammar SP. Cephalosporin-induced interstitial pneumonitis. Chest. 1984;86:138-40.

57. Irie $M$, Teshima $H$, Matsuura $T$, et al. Pulmonary infiltration with eosinophilia possibly induced by cefotiam in a case of steroid-dependent asthma. Nihon Kyobu Shikkan Gakkai Zasshi. 1990;28:1353-8 (in Japanese).

58. Murphy MF, Metcalfe P, Grint PC, et al. Cephalosporin-induced immune neutropenia. Br J Haematol. 1985;59:9-14.

59. Neftel KA, Hauser SP, Muller MR, Walti M. Cephalosporin-induced neutropenia. $\mathrm{Br}$ J Haematol. 1986;62:394-7.

60. Malincarne L, Francisci D, Martinelli L, Masini G, Baldelli F. A case of severe cefepime-related neutropenia in a 15-year-old patient. Scand J Infect Dis. 2010;42:156-7.

61. Hersh AL, Chambers HF, Maselli JH, Gonzales R. National trends in ambulatory visits and antibiotic prescribing for skin and soft-tissue infections. Arch Intern Med. 2008;168:1585-91.

62. Edelsberg J, Taneja C, Zervos M, et al. Trends in US hospital admissions for skin and soft tissue infections. Emerg Infect Dis. 2009;15:1516-8.

63. HCUP facts and figures: statistics on hospital-based care in the United States, 2007. Rockville; 2009. http://www.hcup-us.ahrq.gov/reports/factsand figures/2007/TOC_2007.jsp (Accessed 18 Jan 2013).

64. HCUP facts and figures: statistics on hospital-based care in the United States, 2009. Rockville; 2011. http://www.hcup-us.ahrq.gov/reports/factsand figures/2009/TOC_2009.jsp (Accessed 18 Jan 2013).
65. Dukic VM, Lauderdale DS, Wilder J, Daum RS, David MZ. Epidemics of community-associated methicillin-resistant Staphylococcus aureus in the United States: a meta-analysis. PLoS ONE. 2013;8:e52722.

66. Sakoulas G, Moellering RC Jr. Increasing antibiotic resistance among methicillin-resistant Staphylococcus aureus strains. Clin Infect Dis. 2008;46:S360-7.

67. Lodise TP, Graves J, Evans A, et al. Relationship between vancomycin MIC and failure among patients with methicillin-resistant Staphylococcus aureus bacteremia treated with vancomycin. Antimicrob Agents Chemother. 2008;52:3315-20.

68. Kim SH, Kim KH, Kim HB, et al. Outcome of vancomycin treatment in patients with methicillin-susceptible Staphylococcus aureus bacteremia. Antimicrob Agents Chemother. 2008;52:192-7.

69. Gerson SL, Kaplan SL, Bruss JB, et al. Hematologic effects of linezolid: summary of clinical experience. Antimicrob Agents Chemother. 2002;46:2723-6.

70. Papadopoulos S, Ball AM, Liewer SE, Martin CA, Winstead PS, Murphy BS. Rhabdomyolysis during therapy with daptomycin. Clin Infect Dis. 2006;42:e108-10.

71. Marcos LA, Camins BC, Ritchie DJ, Casabar E, Warren DK. Acute renal insufficiency during telavancin therapy in clinical practice. J Antimicrob Chemother. 2012;67:723-6.

72. Heron M. Deaths: leading causes for 2008. Natl Vital Stat Rep. 2012;60:1-94.

73. DeFrances CJ, Lucas CA, Buie VC, Golosinskiy A. 2006 National Hospital Discharge Survey. Natl Health Stat Report. 2008;30:1-20.

74. Jones RN, Sader HS, Moet GJ, Farrell DJ. Declining antimicrobial susceptibility of Streptococcus pneumoniae in the United States: report from the SENTRY Antimicrobial Surveillance Program (1998-2009). Diagn Microbiol Infect Dis. 2010;68:334-6.

75. Micromedex ${ }^{\circledR}$ Healthcare Series [intranet database]. Version 2.0. Greenwood Village CTRHI.

76. Vidaillac C, Leonard SN, Sader HS, Jones RN, Rybak MJ. In vitro activity of ceftaroline alone and in combination against clinical isolates of resistant Gram-negative pathogens, including betalactamase-producing Enterobacteriaceae and Pseudomonas aeruginosa. Antimicrob Agents Chemother. 2009;53:2360-6. 
77. Wiskirchen DE, Crandon JL, Furtado GH, Williams $G$, Nicolau DP. In vivo efficacy of a humansimulated regimen of ceftaroline combined with NXL104 against extended-spectrum-beta-lactamase (ESBL)-producing and non-ESBL-producing Enterobacteriaceae. Antimicrob Agents Chemother. 2011;55:3220-5.

78. Louie A, Castanheira M, Liu W, et al. Pharmacodynamics of beta-lactamase inhibition by NXL104 in combination with ceftaroline: examining organisms with multiple types of betalactamases. Antimicrob Agents Chemother. 2012;56:258-70.

79. Livermore DM, Mushtaq S, Barker K, Hope R, Warner M, Woodford N. Characterization of betalactamase and porin mutants of Enterobacteriaceae selected with ceftaroline + avibactam (NXL104). J Antimicrob Chemother. 2012;67:1354-8.

80. Castanheira M, Sader HS, Farrell DJ, Mendes RE, Jones RN. Activity of ceftaroline-avibactam tested against Gram-negative organism populations, including strains expressing one or more betalactamases and methicillin-resistant Staphylococcus aureus carrying various staphylococcal cassette chromosome mec types. Antimicrob Agents Chemother. 2012;56:4779-85.

81. Shlaes DM. New beta-lactam-beta-lactamase inhibitor combinations in clinical development. Ann N Y Acad Sci. 2013;1277:105-14.

82. Barbour A, Schmidt S, Rand KH, Derendorf $H$. Ceftobiprole: a novel cephalosporin with activity against Gram-positive and Gram-negative pathogens, including methicillin-resistant Staphylococcus aureus (MRSA). Int J Antimicrob Agents. 2009;34:1-7.

83. van Hal SJ, Paterson DL. New Gram-positive antibiotics: better than vancomycin? Curr Opin Infect Dis. 2011;24:515-20.

84. Riccobene TA, Su SF, Rank D. A single- and multiple-dose study to determine the safety, tolerability, and pharmacokinetics of ceftaroline fosamil in combination with avibactam in healthy subjects. Antimicrob Agents Chemother. 2013;57:1496-504.

85. Jacqueline C, Amador G, Caillon J, et al. Efficacy of the new cephalosporin ceftaroline in the treatment of experimental methicillin-resistant Staphylococcus aureus acute osteomyelitis. J Antimicrob Chemother. 2010;65:1749-52.

86. Cottagnoud P, Acosta F, Accosta F, Eggerman U, Biek D, Cottagnoud M. Ceftaroline is superior to cefepime against a Klebsiella pneumoniae strain an experimental rabbit meningitis model (Abstract number: P1569). Abstracts 20th European Congress of Clinical Microbiology and Infectious Diseases, Vienna; 2010.

87. Ho TT, Cadena J, Childs LM, Gonzalez-Velez M, Lewis JS 2nd. Methicillin-resistant Staphylococcus aureus bacteraemia and endocarditis treated with ceftaroline salvage therapy. J Antimicrob Chemother. 2012;67:1267-70.

88. Rose WE, Schulz LT, Andes D, et al. Addition of ceftaroline to daptomycin after emergence of daptomycin-nonsusceptible Staphylococcus aureus during therapy improves antibacterial activity. Antimicrob Agents Chemother. 2012;56:5296-302.

89. Werth BJ, Sakoulas G, Rose WE, Pogliano J, Tewhey R, Rybak MJ. Ceftaroline increases membrane binding and enhances the activity of daptomycin against daptomycin-nonsusceptible vancomycinintermediate Staphylococcus aureus in a pharmacokinetic/pharmacodynamic model. Antimicrob Agents Chemother. 2013;57:66-73.

90. Marschall J, Lane MA, Beekmann SE, Polgreen PM, Babcock HM. Current management of prosthetic joint infections in adults: results of an Emerging Infections Network survey. Int J Antimicrob Agents. 2013;41:272-7.

91. Jongsma K, Joson J, Heidari A. Ceftaroline in the treatment of concomitant methicillin-resistant and daptomycin-non-susceptible Staphylococcus aureus infective endocarditis and osteomyelitis: case report. J Antimicrob Chemother. 2013;68:1444-5.

92. Liu C, Bayer A, Cosgrove SE, Daum RS, Fridkin SK, Gorwitz RJ, Kaplan SL, Karchmer AW, Levine DP, Murray BE, M JR, Talan DA, Chambers HF. Clinical practice guidelines by the infectious diseases society of America for the treatment of methicillinresistant Staphylococcus aureus infections in adults and children: executive summary. Clin Infect Dis. 2011;52:285-92. 